\title{
POBREZA, POLÍTICAS PÚBLICAS Y POLÍTICAS SOCIALES EN YUCATÁN, 1995-2007
}

\author{
Flavio Ulises Pérez Chi \\ Jefe del departamento de Planeación e Investigación del Instituto para la \\ Equidad de Género en Yucatán. Maestro en Gobierno y Políticas Públicas \\ por la Facultad de Economía de la Universidad Autónoma de Yucatán (UADY).
}




\section{INTRODUCCIÓN}

El presente trabajo de investigación analiza la pobreza en el marco de las políticas públicas, en la cual, se estudió el proceso de institucionalización de la pobreza, los problemas que presentan las políticas públicas orientadas al combate a la pobreza, las acciones de combate a la pobreza que se han implementado durante dos gestiones gubernamentales en el Estado de Yucatán y se elaboró un diagnóstico de la situación de la pobreza que se vive en Yucatán con el fin de comprobar la hipótesis central, en la cual, se establece que el proceso de institucionalización de la pobreza en el Estado de Yucatán ha sido pausado y gradual respondiendo tardíamente a esta problemática social y económica.

A través de esta investigación, se busca contribuir al conocimiento de la pobreza en el Estado de Yucatán con el estudio de las políticas públicas que han sido implementadas desde que el tema de la pobreza empezó a acaparar el interés de las autoridades gubernamentales, tomando como referencia los periodos de análisis 1995-2001 y 2001-2007, especialmente, desde que se institucionalizaron las acciones de combate a la pobreza con la creación de la Secretaría de Desarrollo Social, actualmente, llamada Secretaría de Política Comunitaria y Social.

El estudio parte del proceso de institucionalización de la pobreza, es decir, como forma parte de la agenda pública y el inicio en la elaboración e implementación de políticas públicas. Desde el periodo posrevolucionario, cuando se empezó a formar el sistema político mexicano, se dio paso a la restauración de las condiciones para la realización de las actividades económicas, estimular el crecimiento económico a partir de la nueva visión del Estado revolucionario e incorporación de las aspiraciones sociales. En ese periodo, los ejércitos revolucionarios pasaron a ser partidos políticos, los planes y proclamas se convirtieron en idearios, los cuales la mayoría quedó plasmada en la Constitución Política de los Estados Unidos Mexicanos.

La pobreza es producto de las externalidades negativas que genera el sistema económico que hemos adoptado. Las decisiones que se toman en el mercado donde se desarrollan las leyes de la oferta y la demanda de los bienes y servicios que genera la sociedad, crea costos a la propia sociedad, el cual tiene 
efectos sociales, como es el aumento generalizado del número de personas que se incorporan a las filas de la pobreza, tal es el caso, de las personas que quedan excluidas del propio mercado creándose grupos marginados y excluidos; como se ve en la realidad, todo aquel ser humano que viva marginado, explotado o pobre será víctima de la explotación de otras personas y de las leyes del mercado. Por ello, el Estado interviene con el desarrollo e implementación de políticas públicas de combate a la pobreza, que en teoría debe hacer que la inversión pública sea efectiva y fomentar intervenciones selectivas para estimular un círculo virtuoso de crecimiento económico y reducción de la pobreza.

En el Estado posrevolucionario, no se desarrolló e implementó políticas públicas específicas en el combate a la pobreza, lo primordial era restaurar las condiciones para el desarrollo de las actividades económicas, ya que se daba por entendido que la generación de empleos impediría la pobreza en el país, lo cual no ocurrió así. México, se ha mantenido desde el periodo posrevolucionario como país subdesarrollado, con una disparidad de desarrollo entre los Estados que lo componen, unos Estados ricos y otros Estados pobres.

Los proyectos sociales que se implementaban a favor de las personas que eran excluidos de los beneficios económicos que generaba la dinámica económica de la sociedad (antes que se lleven a cabo acciones institucionales) provenían de la propia Iglesia. Durante la colonia española en México y aún después de la independencia, la Iglesia fue un actor muy importante en las decisiones del país, especialmente a lo que se refiere a los ámbitos de educación y religiosidad. Fue hasta en 1977, cuando se dan los primeros pasos en la asistencia social con la creación del Sistema Nacional para el Desarrollo Integral de la Familia (DIF).

En México, se han desarrollado e implementado varias políticas económicas, desde políticas planificadoras con una alta participación del Estado en la economía (de corte socialista) como se dio en el periodo del desarrollo estabilizador (1958-1974) en la cual, se estableció el crecimiento del PIB industrial por encima del PIB agropecuario, proteccionismo comercial, subsidios superiores a la carga fiscal, límites a los salarios y precios agrícolas, déficit en las cuentas públicas, concentración del ingreso, producción y consumo suntuario, dependencia tecnológica y desequilibrio externo; hasta políticas 
neoliberales con una baja participación del Estado que dan pie al desarrollo de las políticas públicas para abatir los variados problemas sociales. Una hipótesis que se establece en la investigación es que las políticas públicas de corte social que se implementan actualmente están condicionadas por el sistema económico neoliberal que no ha contribuido lo suficiente para combatir la pobreza. Además la correlación de fuerzas políticas (partidos políticos, ONG's, grupos de presión, entre otros) dentro del escenario político nacional determinan el molde de las políticas públicas que el gobierno federal, estatal y municipal elaborarán e implementarán.

El gobierno propuso una nueva relación con la sociedad, una vez que se empezó a agotar el esquema corporativista construido por la revolución. En la práctica, las políticas sociales estaban encaminadas a mantener el control político mediante políticas de transferencias monetarias o acceso de servicios, en vista del creciente pluralismo y el fin de la era intervencionista del Estado; las agencias gubernamentales se convirtieron en las instituciones clave para el financiamiento e implementación de los programa públicos.

Sería hasta finales del siglo XX cuando se empezó a formar una red de políticas (concepto usado para explicar la relación entre agencias gubernamentales y grupos sociales) para el combate a la pobreza con la creación en 1992 de la Secretaría de Desarrollo Social (SEDESOL) a partir de la fusión de la Secretaría de Desarrollo Urbano y Ecología (SEDUE) y la Secretaría de Programación y Presupuesto (SPP), quien manejaba el Programa Nacional de Solidaridad (PRONASOL). La SEDESOL tiene la responsabilidad de lograr la superación de la pobreza mediante el desarrollo humano integral incluyente y corresponsable, para alcanzar niveles suficientes de bienestar con equidad, mediante las políticas y acciones de ordenación territorial, desarrollo urbano y vivienda, mejorando las condiciones sociales, económicas y políticas en los espacios rurales y urbanos.

De la misma forma, se observó el cambio de visión en el Estado yucateco, con la modificación de la estructura orgánica del gobierno y de las secretarías con la creación en el año 2001 de la Secretaría de Desarrollo Social, llamada actualmente, Secretaría de Política Comunitaria y Social del Estado de Yucatán con la reforma de la Ley Orgánica de la Administración Pública del Estado de Yucatán ${ }^{1}$. Esta tiene como responsabilidad desarrollar políticas, programas y 
proyectos destinados a combatir la pobreza y elevar el nivel de calidad de vida de los yucatecos, procurando siempre lograr el bienestar integral de la población. Sería hasta inicios del siglo XXI cuando se empieza a entretejer una red de políticas sociales.

\section{ASPECTOS CONCEPTUALES}

\section{Pobreza}

La categoría de pobreza no es una creación moderna, aunque sí lo sean algunos de sus contenidos. Por el contrario, tiene una larga tradición en la mayoría de las culturas y en cada una se manifiesta diversamente y su significado ha evolucionado con el tiempo. De esta continua y variada presencia, no resulta fácil deducir un concepto único de pobreza de validez universal, así que su concepto se ha definido y se define de acuerdo al contexto social y económico y de las características y objetivos en torno a los que se organiza la sociedad (Dubois et. al, 2005).

Existe una variedad de conceptos sobre la pobreza procedente de varios autores e instituciones internacionales, que han establecido bases teóricas y conceptuales para la discusión del tema principal: pobreza y políticas públicas. El concepto de pobreza ha evolucionado en su definición pasando de una visión unidimensional puramente económica hasta incluir una visión multidimensionalidad.

Existen diversos enfoques para estudiar y comprender la pobreza en diferentes sociedades y a lo largo del tiempo. Algunos especialistas de las ciencias sociales y, especialmente los economistas, se refieren casi exclusivamente a los ingresos, al consumo y, hasta cierto punto, al bienestar humano, como elementos para entender y medir la condición de pobreza de las personas. En este sentido, el concepto de bienestar económico nace de la realidad de si una persona tiene suficientes ingresos para adquirir una cesta de consumo mínima necesaria para satisfacer sus necesidades de alimento. Otros especialistas de

\footnotetext{
${ }_{1}^{1}$ Decreto No. 21 publicado en el Diario Oficial Núm. 30961 con fecha del 16 de octubre de 2007 donde se establece el Código de la Administración Pública de Yucatán, Título IV, Capítulo VIII. 
las ciencias sociales han visto la pobreza como una función de la falta de capacidades individuales, como la educación o la salud, para alcanzar un nivel básico de bienestar humano. Y otros estudiosos, especialmente los sociólogos y antropólogos, se han concentrado en los factores sociales, comportamentales y políticos del bienestar humano. En este sentido, si bien se percibe como causa de la pobreza el comportamiento anormal o el aislamiento, existen argumentos divergentes para definir quién (los propios individuos o las instituciones) convierte a los pobres en personas anormales o aisladas del resto de la sociedad (Wagle, 2002).

\section{La pobreza en la agenda pública}

Anteriormente, la pobreza no era un tema que les interesara a los políticos y a otros actores de la sociedad, tuvieron que pasar varios años para que se establezca en la agenda pública cuando la magnitud del problema se incrementó y estaba en riesgo la estabilidad social. Por formación de una agenda se entiende el proceso a través del cual ciertos problemas o cuestiones llegan a llamar la atención seria y activa del gobierno como posibles asuntos de política pública.

El tema de la pobreza comenzó a tener presencia en la agenda pública de México durante el sexenio de Luis Echeverría Álvarez, cuando se creó la Coordinación del Plan Nacional para Zonas Deprimidas y Grupos Marginados (COPLAMAR), que en 1977 aplicó programas para combatirla. Éstos se destinaron a zonas oprimidas, en especial las rurales y los grupos marginados. En esos tiempos, el Estado tenía una fuerte presencia en la economía (economía intervencionista) donde las libertades económicas y políticas eran mínimas. Actualmente está disminuyendo su presencia (economía neoliberal) a través de las privatizaciones y desregulaciones.

A los programas de combate a la pobreza llevados a cabo por COPLAMAR, se unió el Sistema Alimentario Mexicano; sin embargo, debido a la crisis económica que sufrió México por la caída de los precios del petróleo estos programas fueron abandonados. Fue hasta 1988, en el sexenio de Carlos Salinas de Gortari, que se creó el Programa Nacional de Solidaridad que pretendía mitigar la pobreza definiéndola como un problema de falta de ingresos y escaso acceso a una serie de servicios (como la educación, la salud, la vivienda, etc.). En el sexenio de Ernesto Zedillo Ponce de León (1994-2000), se llevó a 
cabo el Programa Nacional de Educación, Salud y Alimentación (PROGRESA) que pretendería unir acciones de educación, salud, y alimentación para las familias más pobres de México, centrando la atención en el núcleo familiar, en los niños y en las niñas, dejando la gran responsabilidad en las madres de familia. Con el sexenio de Vicente Fox Quesada (2000-2006), el Programa OPORTUNIDADES reunió los esfuerzos de varias secretarías de Estado, entre los que se encuentran la Secretaría de Desarrollo Social (SEDESOL), la Secretaría de Educación Pública (SEP), la Secretaría de Salud y Asistencia (SSA), así como el Instituto Mexicano del Seguro Social (IMSS) y diversos organismos que trabajarían de manera coordinada para avanzar en el combate a la pobreza. Hoy en día, se lleva a cabo el Programa OPORTUNIDADES, bajo la gestión de Felipe Calderón Hinojosa.

La pobreza es un fenómeno económico y social que afecta a un gran número de personas y familias de todas partes del mundo, aunque este flagelo social se vive mayormente en los países en desarrollo cuya población constituyen una tercera parte del total mundial. Es una amenaza a la seguridad social, a partir de esto, se necesita tomar medidas urgentes para disminuir este problema. México es un país en desarrollo que sufre los estragos de la pobreza (no solo rural sino también urbana) diseminada en sus treinta y dos entidades federativas. A medida que pasa el tiempo un gran número de personas se incorporan a las filas de la pobreza, incluso la pobreza va de generación en generación y disminuye la posibilidad de las personas de ejercer su racionalidad, su voluntad de plantearse fines y de buscar los medios más adecuados para llevarlos a cabo. Se menciona que ahondar en las raíces de la pobreza supone plantear cuestiones difíciles y conflictivas, lo que explica las reticencias y los rechazos que acompañan el proceso del conocimiento de la pobreza.

Un dato importante a señalar, es que no solo basta que un tema esté en la agenda pública, sino también es necesario que se legisle sobre el tema, ya que el imperativo legal es de suma importancia al momento de elaborar e implementar una política pública. El Gobierno Federal público la Ley General de Desarrollo Social en el 2004, esta Ley establece la creación de una Política Nacional de Desarrollo Social y de un Sistema Nacional de Desarrollo Social. Ocho Estados ya cuenta con una Ley Estatal que regula las acciones de política social, siendo el Distrito Federal, como el Estado más adelantado en cuestiones sociales, ya que público su ley cuatro años antes que la federal. 


\section{Política pública}

Uno de los componentes importantes en la elaboración de una política pública es la definición del problema. La pobreza se ha definido con variables puramente económicas, cuyo alcance queda limitado para entender la complejidad del problema. Los nuevos estudios sobre la definición de la pobreza incorporan variables no estrictamente económicas inclinándose al desarrollo de capacidades y oportunidades del individuo. Su definición dependerá del enfoque que se desea estudiar. En la actualidad, su medición está basada en los ingresos y en el consumo en relación a una canasta básica de bienes y servicios ya establecida; es el enfoque más usado para definir la pobreza a pesar de que existen otros, como es la pobreza de capacidades que analiza aquellos factores que impiden a los individuos disfrutar de suficiente bienestar humano; las capacidades de las personas pueden asumir múltiples dimensiones, como la educación, la salud y otros, y produce un mayor impacto en el bienestar, incluyendo la generación de ingresos necesarios para aumentar el consumo de bienes y servicios. Y la exclusión social, que se ha definido de muchas maneras, es el proceso mediante el cual los individuos o grupos son total o parcialmente excluidos de una participación plena en la sociedad en que viven.

La definición y medición del problema es de suma importancia al momento de elaborar una política pública, ya que su utilidad dependerá de que tan bien esté definido y medido el problema. Existen tres métodos para medir la pobreza: 1) el de líneas de pobreza, 2) el de necesidades básicas insatisfechas y 3) el método integrado. El método recomendado por el Comité Técnico para la Medición de la Pobreza en México es de carácter monetario, también denominado Líneas de Pobreza (LP).

La información cuantitativa y cualitativa que se genera en torno a la pobreza es de suma importancia para orientar decisiones públicas y privadas que intenten reducir la brecha entre los municipios altamente desarrollados y aquellos rezagados. Yucatán, como el resto del país, es un Estado de contrates sociales y económicos donde prevalece la inequidad en la distribución del ingreso y en donde los habitantes de los municipios más marginados del Estado no tienen el suficiente recurso monetario para adquirir lo mínimo de la canasta básica. Esta situación desencadena una serie de problemas propios de 
la pobreza, como es la desnutrición, el analfabetismo, el hacinamiento al aire libre, viviendas inadecuadas, entre otras.

Un dato importante a destacar, es que con la creación de instituciones federales y estatales para la elaboración de políticas públicas sociales se comienza a establecer los cimientos de una red de políticas. El concepto de redes de políticas se usa crecientemente para explicar la relación entre agencias gubernamentales y grupos sociales. De hecho, la incorporación de conceptos de redes (intergubernamentales, intragubernamentales, interorganizacionales) en los estudios sobre organizaciones, política y políticas públicas han ganado importancia, en la medida que el gobierno empezó a ser concebido como una institución plural y fragmentada, matizada por múltiples intereses (Vargas, 2007).

Crucial al nuevo institucionalismo ${ }^{2}$ es el concepto de red de políticas. Considerado como un nivel intermedio, la red de políticas es un concepto de intermediación de intereses de grupo que se acomodan a diferentes modelos de distribución de poder en las democracias liberales. Sin embargo, en los países subdesarrollados, particularmente en América Latina, la red de políticas tiene retos mayores, en vista de que los modelos sistémicos de interpretación social, tales como el pluralismo/elitismo o el marxismo, tienen serias dificultades para interpretar sistemas políticos "atípicos" o democracias imperfectas, conduciendo a la construcción o diseño de modelos locales (Vargas, 2007).

El nuevo institucionalismo ha destacado la interdependencia entre instituciones sociales y políticas relativamente independientes, más que el predominio del régimen político, así como la reconstrucción de instituciones complejas para entender el proceso político (Ibíd.).

Los múltiples modelos de redes de política coinciden con siete hipótesis básicas: a) las instituciones políticas afectan la política, b) la acción burocrática se lleva a cabo en un contexto institucional, c) las instituciones públicas o

\footnotetext{
${ }^{2}$ Todo proceso de institucionalización conlleva una dialéctica de tensión y conflicto entre los "nuevo" y los "viejo", que se expresa mediante la resistencia, la resignificación y la transformación continúa de los contenidos de las prácticas existentes. Esto significa que no sucede de forma lineal ni homogénea, por el contrario, puede considerarse un proceso discontinuo en el que los avances en un plano, generalmente el legal, no se reflejan de manera inmediata en las prácticas cotidianas institucionales.
} 
privadas pueden colapsarse dentro de las organizaciones, d) no hay separación significativa entre organizaciones y su personal, e) las organizaciones son cuerpos sociales que controlan los ambientes en las que operan, f) las organizaciones son actores políticos en sí mismos, y g) la distribución de recursos entre organizaciones es un centro de poder, mientras que el desempeño organizacional puede intensificar ese poder (Ibíd.).

\section{IMPLEMENTACIÓN DE LA POLÍTICA PÚBLICA}

La implementación de las políticas abarca aquellas acciones efectuadas por individuos (o grupos) públicos y privados, con miras a la realización de objetivos previamente decididos. La fase de implementación no comienza sino hasta después que las decisiones previas han establecido (o identificado) los objetivos y metas. De igual forma, la implementación tiene lugar sólo después de que la legislación ha sido promulgada y de que los fondos han sido asignados (Van Meter y Van Horn, 2003).

Dado las características del sistema en que vivimos, los elaboradores de políticas públicas buscaran cambios incrementales, que no perjudiquen las leyes de la oferta y la demanda. Charles E. Lindblom menciona, que los administradores públicos y los analistas de políticas limitan su análisis en gran medida a las diferencias marginales o incrementales de las políticas, las que a su vez se eligen porque difieren solo incrementalmente. No lo hacen, sin embargo, tan sólo porque necesitan con urgencia simplificar sus problemas, sino también para ser pertinentes. En efecto, las democracias cambian sus políticas casi siempre a través de ajustes incrementales, no se mueven a grandes saltos (Lindblom, 2003).

Las democracias deben aceptar un grado relativo de incrementalismo (aunque no tan elevado como los países en desarrollo), debido a que sus nuevas decisiones tienen mayor necesidad de apoyo por parte de los muchos y variados sectores sociales, situación que reduce su capacidad para emprender un plan de largo alcance. Es más fácil lograr el consenso en situaciones normales o para modificaciones incrementales de las políticas existentes, que para emprender una nueva política. El papel de las crisis es muy significativo en este sentido; en las democracias menos pasivas, las crisis sirven para obtener 
consenso en torno a cambios fundamentales de dirección. Las sociedades totalitarias, mas centralistas, basadas en fuerza que dependen menos del consenso, pueden planear más, pero tienden exagerar las metas. A diferencia de las democracias, en las que busca primero obtener consenso y después actuar, con realizaciones menos ambiciosas y a más largo plazo, las sociedades totalitarias generalmente intentan demasiado y demasiado pronto debido a que no necesitan buscar el consenso o evaluar las diversas resistencias (Etzioni, 2003).

Se parte del supuesto de que la eficiencia de la implementación depende, parcialmente, del tipo de política en cuestión y de que los factores específicos que facilitan o impiden la realización de los objetivos de un programa suelen variar de un tipo de política a otro. La hipótesis apunta que la implementación tendrá más éxito cuando sólo se requieren cambios marginales y cuando el consenso en torno a las metas sea alto.

Hoy en día, el modelo económico vigente (capitalismo) que se lleva a cabo en México y en el Estado de Yucatán sostiene que el crecimiento económico es, y debe ser, el motor de la reducción de la pobreza. Sin embargo, la realidad nos describe otro escenario ya que esto no ha sido así hasta ahora, a pesar de que el crecimiento económico en otros países se ha traducido en resultados muy distintos en materia de reducción de la pobreza. Varios estudios mencionan que uno de los factores que determina si el crecimiento se traduce o no en reducciones significativas de la pobreza, es el grado de desigualdad; la pobreza real disminuye conforme se reduce la desigualdad en la distribución del ingreso y de la riqueza, y conforme se aminoran las disparidades entre géneros y grupos étnicos. Por ello, la superación de ciertas desigualdades estructurales es un componente crucial de toda estrategia de lucha contra la pobreza.

Por ello, es importante elaborar e implementar políticas públicas de corte social que reduzcan las desigualdades en los ingresos y no basarse en únicamente en el crecimiento económico para disminuir la pobreza. Actualmente, los sectores económicos más conservadores y privilegiados suelen temer que una mayor igualdad redunde en perjuicio del crecimiento. Sin embargo, los estudios empíricos suelen demostrar, en cambio, que sociedades más igualitarias pueden crecer con mayor rapidez. 


\section{Metodología}

Se utilizó un diseño de comprobación: 1) no experimental longitudinal tendencial que fue el plan o estrategia concebida para aceptar o rechazar las hipótesis establecidas en la presente investigación. En esta investigación no se manipularon las variables de análisis y se recabó información en dos diferentes puntos a través del tiempo, los periodos de gobierno 1995-2001 y 20012007, con el fin de analizar los cambios en lo referente a la elaboración e implementación de políticas públicas de corte social.

Este diseño nos sirvió para observar los fenómenos tal y como se dan en el contexto de estudio, recolectando información en diversos puntos o periodos específicos (longitudinal), para posteriormente analizar sus determinantes y consecuencias, y su incidencia.

La presente investigación analizó varios temas (pobreza, políticas públicas, sistema económico neoliberal, descentralización, federalismo, ciudadanía, democracia, controles políticos, arena política, entre otros temas) de manera combinada, lo cual le da al trabajo un mayor valor agregado. Se utiliza la perspectiva institucional para destacar las actividades, acciones, políticas y conflictos que ocurren en un marco de elaboración de políticas públicas sociales y no en espacio vacío.

El desarrollo e implementación de políticas públicas sociales es sumamente complejo por todo lo que gira a su alrededor. Una estrategia de lucha contra la pobreza no puede reducirse sólo a mantener un sistema de mercado donde las leyes de la oferta y la demanda determinen la distribución del ingreso dejando a un lado a la sociedad y el Estado. A través del tiempo, se ha observado una avance en el diseño de políticas públicas, donde se está dando un proceso de descentralización con miras al fortalecimiento del federalismo que otorgan al municipio un reconocimiento como tercer orden de gobierno, sin embargo, la escasa profesionalización de los servidores públicos municipales dificulta el proceso mencionado cuyo fin es un desarrollo desde lo local. 
En relación a lo anterior se establecieron cuatro objetivos.

\section{Objetivos}

\section{Objetivo general}

Analizar el problema de la pobreza en Yucatán en el marco de las políticas públicas.

\section{Objetivos específicos:}

1. Estudiar el proceso de institucionalización de la pobreza en la agenda pública.

2. Analizar los problemas que presentan las políticas públicas de combate a la pobreza en la implementación.

3. Conocer las acciones de combate a la pobreza que se han implementado durante dos gestiones gubernamentales en el Estado de Yucatán.

4. Analizar la pobreza en el Estado de Yucatán.

\section{Hipótesis}

Se estableció cuatro proposiciones tentativas en esta investigación con enfoque cualitativo que responde a los planteamientos establecidos. Tres descriptivas y una de relaciones de causalidad bivariada donde se establece la relación entre dos variables y cómo se dan dichas relaciones. 


\section{Mapa conceptual de la hipótesis planteada en la investigación}

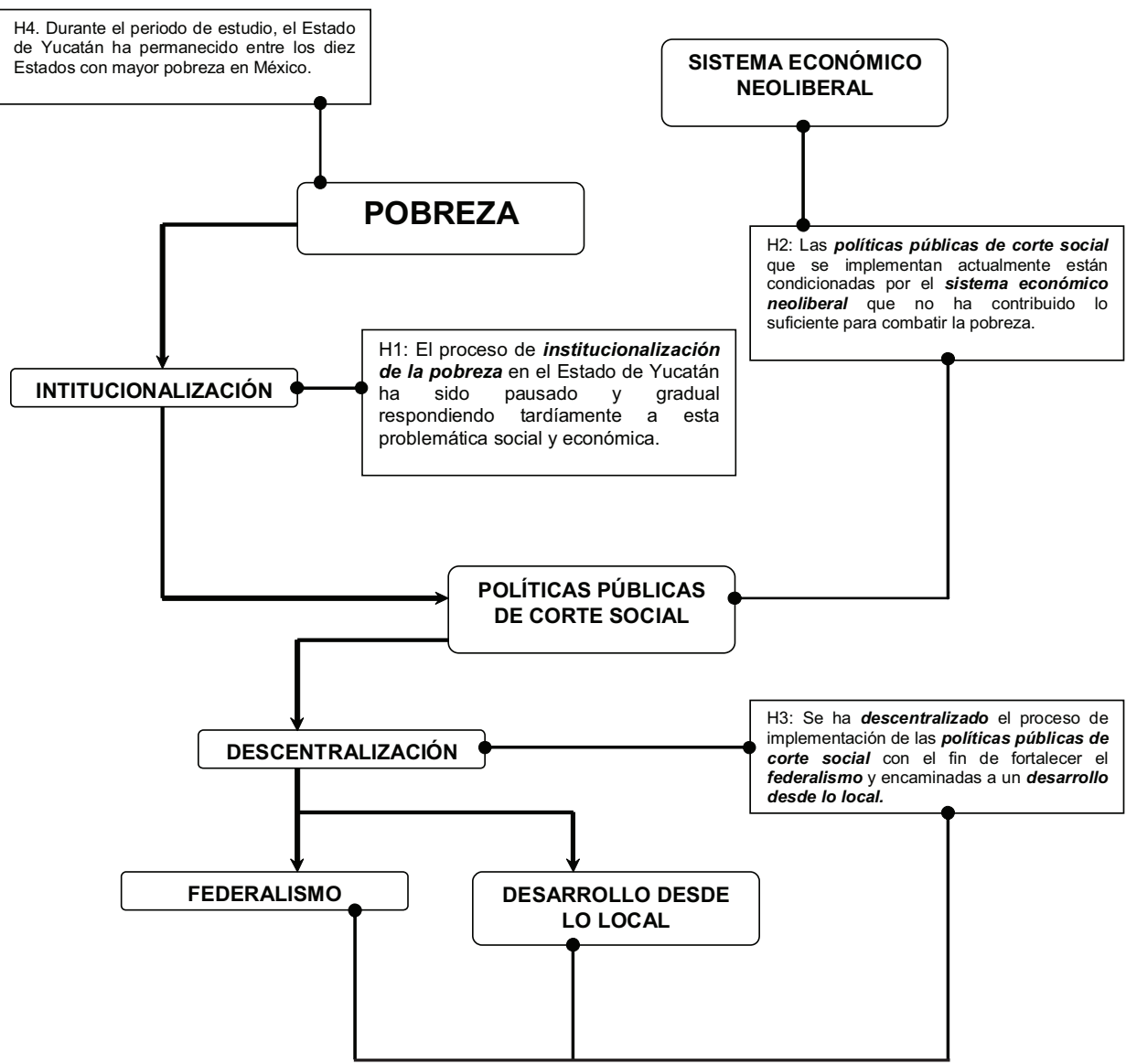

\section{LA POBREZA EN YUCATÁN}

En cuanto a marginación, en el 2005:

- 10 de cada 100 personas es analfabeta

- 30 de cada 100 personas de 15 años y más no tiene la primaria completa

- 17 de cada 100 viviendas no tiene drenaje ni servicio sanitario

- 2 de cada 100 ocupantes en viviendas no cuentan con energía eléctrica

- 3 de cada 100 ocupantes en viviendas no cuentan con agua entubada 
- 3 de cada 100 ocupantes en viviendas no cuentan con agua entubada

- 48 de cada 100 viviendas cuentan con algún nivel de hacinamiento

- 5 de cada 100 ocupantes en viviendas cuentan con piso de tierra

- 63 de cada 100 personas ocupadas cuentan con un ingreso de hasta 2 salarios mínimos

- 6 municipios del Estado tuvieron un índice de marginación muy alto

- 69 municipios del Estado tuvieron un índice de marginación alto

- 26 municipios del Estado tuvieron un índice de marginación medio

- 4 municipios del Estado tuvieron un índice de marginación bajo

- Solamente el municipio de Mérida tuvo un índice de marginación muy bajo

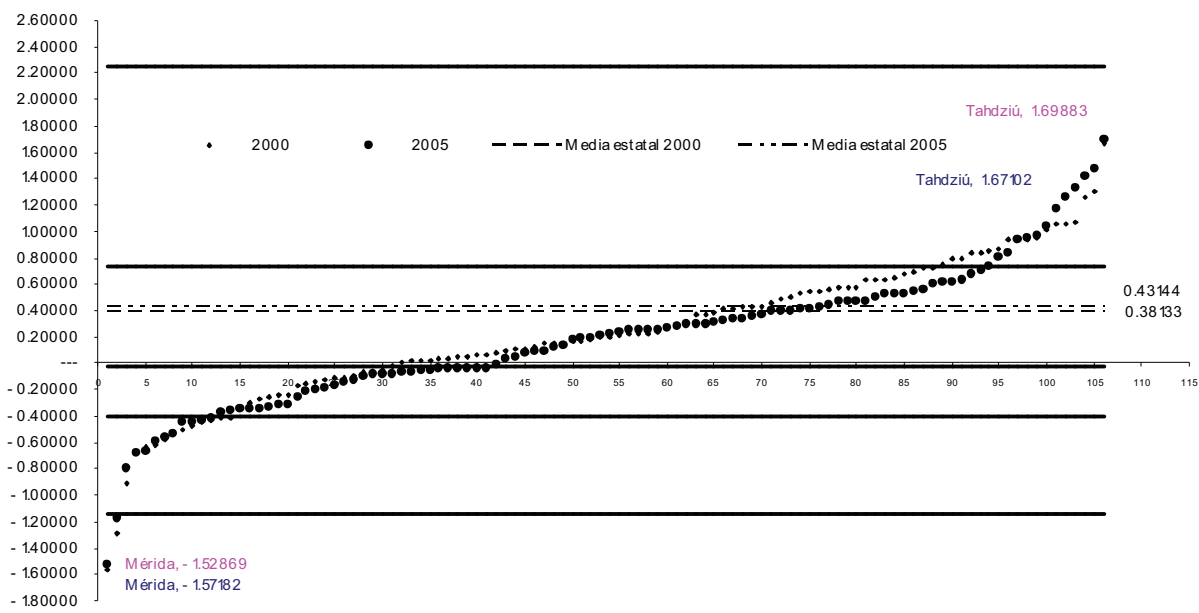

Fuente: Estimaciones del CONAPO. Índice de Marginación Municipal. Estado de Yucatán, 2005

En cuanto a desarrollo humano, en el 2000:

- 27 decesos por cada 1000 nacidos vivos

- 87 de cada 100 personas de 15 años o más es alfabeto

- 64 de cada 100 personas 6 a 24 años van a la escuela

- 6,341 dólares por cada habitante (PIB per cápita en dólares ajustados)

- 3 municipios del Estado tuvieron un índice de desarrollo humano alto

- 81 municipios del Estado tuvieron un índice de desarrollo humano medio alto 
- 22 municipios del Estado tuvieron un índice de desarrollo humano medio bajo

- Ningún municipio del Estado obtuvo un índice de desarrollo humano bajo

- La contribución de los índices parciales de salud, educación e ingreso al IDH es el siguiente: en salud contribuye con el 36\%, educación con el $34 \%$ e ingreso con el $30 \%$

Fuente: Estimaciones del CONAPO. Índice de desarrollo humano. Estado de Yucatán, 2000.

En cuanto a la pobreza, en el 2005:

- 18 de cada 100 personas padecen pobreza alimentaria

- 26 de cada 100 personas padecen pobreza de capacidades

- 51 de cada 100 personas padecen pobreza de patrimonio

- 10 de cada 100 personas de 15 años o más es analfabeta

- 4 de cada 100 personas de 6 a 14 años no asiste a la escuela

- 51 de cada 100 personas de 15 años y más cuenta con educación básica incompleta

- 42 de cada 100 hogares con población de 15 a 29 años, con algún habitante cuenta con menos de 9 años de educación aprobados

- 44 de cada 100 personas no cuenta con derechohabiencia a servicios de salud

- 4 de cada 100 viviendas particulares habitadas cuentan con piso de tierra

- 20 de cada 100 viviendas particulares habitadas no disponen de excusado o sanitario

- 6 de cada 100 viviendas particulares habitadas no disponen de agua entubada de la red pública

- 27 de cada 100 viviendas particulares habitadas no disponen de drenaje

- 5 de cada 100 viviendas particulares habitadas no disponen de energía eléctrica

- 36 de cada 100 viviendas particulares habitadas no disponen de lavadora

- 30 de cada 100 viviendas habitadas no disponen de refrigerador 
- El promedio de ocupantes por cuarto es de 1.25

- 14 municipios del Estado tuvieron un rezago social alto

- 47 municipios del Estado obtuvieron un rezago social medio

- 35 municipios del Estado tuvieron un rezago social bajo

- 10 municipios del Estado obtuvieron un rezago social muy bajo

Fuente: Estimaciones del CONEVAL. Pobreza alimentaría. Estado de Yucatán, 2005
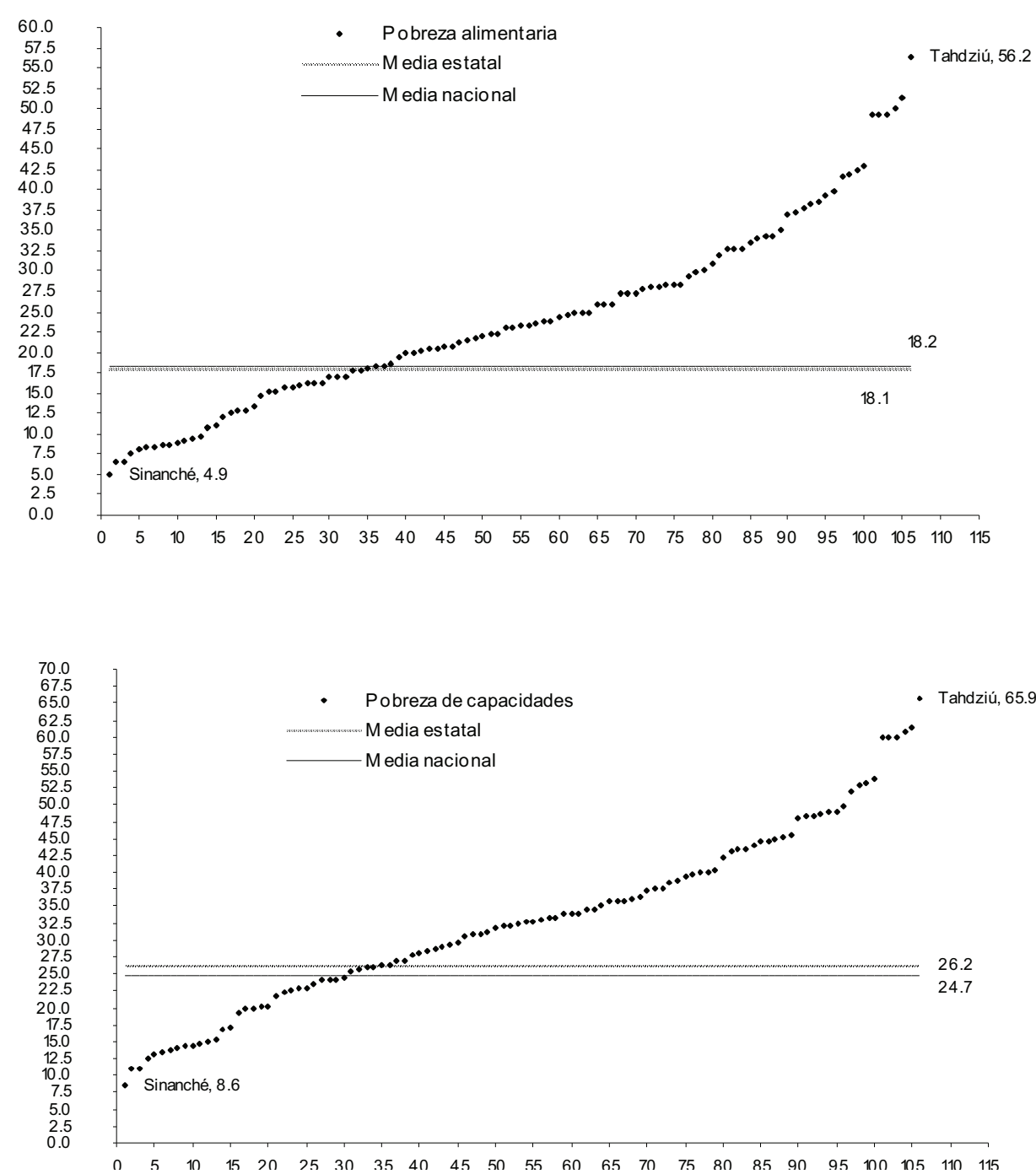


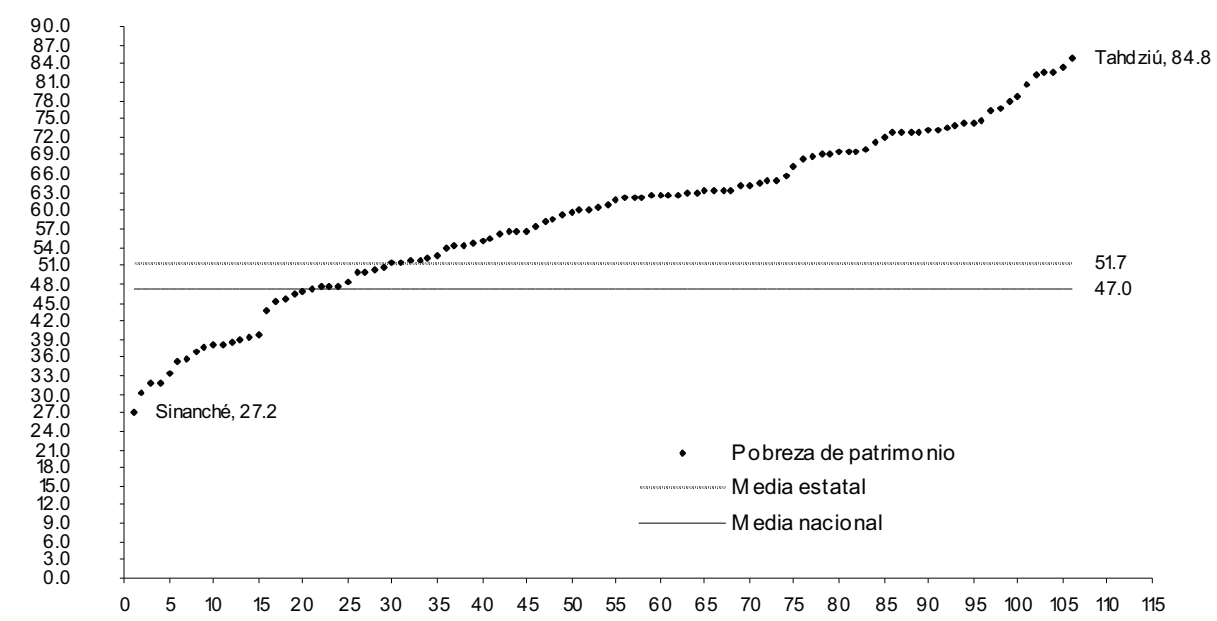

\begin{tabular}{|l|c|c|}
\hline Índice de Rezago Social & \multicolumn{2}{|c|}{ Año 2005 } \\
\hline Absolutos & Población & Municipios \\
\hline Alto & 1818948 & 106 \\
\hline Medio & 111287 & 14 \\
\hline Bajo & 430257 & 47 \\
\hline Muy Bajo & 362851 & 35 \\
\hline Porcentaje Total & 914553 & 10 \\
\hline Alto & $100.0 \%$ & $100.0 \%$ \\
\hline Medio & $6.1 \%$ & $13.2 \%$ \\
\hline Bajo & $23.7 \%$ & $44.3 \%$ \\
\hline Muy Bajo & $19.9 \%$ & $33.0 \%$ \\
\hline
\end{tabular}

Fuente: Estimaciones del CONEVAL. Pobreza alimentaría. Estado de Yucatán, 2005

\section{LA POLÍTICA SOCIAL EN YUCATÁN 1995-2007}

\section{5-2001}

Cervera Pacheco gobernó el Estado entre 1995-2001. Fue un hábil político otrora echeverrista y ya para entonces modernizador convencido, instaló de 
lleno en las esferas del gobierno estatal el proyecto delamadrilista-salinista: privatización de empresas públicas, austeridad presupuestaria, desregulación de la actividad económica, reorientación del aparato productivo hacia el exterior y activa promoción de la inversión extranjera. La modernización neoliberal llegó a Yucatán con él (Canto, 2001).

A lo largo del sexenio 1995-2001 hubo cambios en la estructuración de los recursos de las políticas sociales ${ }^{3}$. Ésta se llevo a cabo en un marco de descentralización federal con el fin de avanzar en un nuevo federalismo ${ }^{4}$, en la cual, el Estado y Municipio se convierten en promotores y hacedores de acciones que contribuyen a mitigar las disparidades en el desarrollo regional.

En el contexto de la descentralización de responsabilidades y los recursos, expresados por el nuevo federalismo, la SEDESOL es la dependencia responsable de instrumentar la política de desarrollo social del Ejecutivo Federal y se coordina con los Estados a través de la firma de Convenios de Desarrollo Social5.

En el marco del Convenio de Desarrollo Social ${ }^{6}$ se destinaron recursos para promover el empleo temporal y la capacitación de los trabajadores, desarrollo de infraestructura (vialidades: - construcción, reconstrucción, modernización - electrificación, agua potable y alcantarillado) y mejoramiento de viviendas. Los recursos se ejercieron a través del ramo 20 y 26.

\footnotetext{
${ }^{3}$ En 1977, el gobierno mexicano mediante COPLAMAR (Coordinación del Plan Nacional para Zonas Deprimidas y Grupos Marginados) aplicó programas de combate a la pobreza. Este tipo de políticas sociales se caracterizaron por la centralización en su diseño, por la escasa intervención de los Estados y municipios en su diseño y ejecución, por una baja participación ciudadana y de otros actores sociales y por una multiplicidad de políticas sectoriales muchas veces contradictorias entre sí.

${ }^{4}$ Nuevo federalismo. Espíritu del artículo 115 constitucional: que los municipios sean la célula básica del desarrollo del país, fortaleciendo la capacidad de los ayuntamientos a fin de que sus autoridades se conviertan en los promotores, gestores, administradores y ejecutores de las obras y acciones que sus habitantes demanden.

${ }^{5}$ Estos convenios se firman cada año. Antes de 1995, la asignación de los recursos a los Estados era totalmente discrecional. De 1995 a 1998 existieron convenios con los

Estados, orientados hacia el fortalecimiento de sus finanzas, desendeudamiento y compromisos de transparencia fiscal.

${ }^{6}$ Los recursos del Ramo 20, "Desarrollo Social", son recursos destinados para complementar el ingreso de las familias y mejorar su nivel de consumo, así como propiciar que las familias decidan la mejor manera de ejercer ese poder de compra adicional. De ese ramo se destinaron recursos para la operación del Programa de Educación, Salud y Alimentación (PROGRESA), ahora llamado OPORTUNIDADES.
} 
A través del ramo 20 y 26 se llevaron a cabo varios programas con recursos para promover el empleo temporal, la capacitación de los trabajadores, construcción y reparación de albarradas, impulso a la instalación de maquiladoras, desarrollo de infraestructura de vialidad (construcción, reconstrucción, modernización de calles), electrificación, agua potable y alcantarillado y mejoramiento de viviendas con el fin de promover el desarrollo integral de las comunidades y familias en situación de pobreza, la generación de ingresos y de empleo y al desarrollo regional, privilegiando a aquellas regiones del Estado en condiciones de rezago y marginación, y las áreas y grupos sociales convenidos conforme a los indicadores de pobreza.

El proceso de descentralización de los recursos federales continuó, dando un viraje hacia lo local en el combate a la pobreza y la marginación económica y social, aunque estableciendo mecanismos de control, en ese proceso se descentralizó las responsabilidades en el manejo de recursos a través de la creación del ramo 33, llamado "Aportaciones Federales para Entidades Federativas"7, compuesto inicialmente en cinco fondos y posteriormente aumentó a ocho ${ }^{8}$.

2001-2007

Patricio Patrón Laviada gobernó el Estado en el periodo 2001-2007, procedió de un partido distinto al gobierno del sexenio pasado, un partido que representa el conservadurismo en Yucatán. El ascenso electoral de la derecha no ha sido ajeno, desde luego, es el voto de castigo a los desaciertos del régimen y el desgaste del PRI, observable no sólo en Yucatán sino en todo el país (Canto, 2001).

${ }^{7}$ El Ramo 33 Aportaciones Federales para Entidades Federativas y Municipios surge de la integración de programas y recursos que anteriormente se ejercían a través de los Ramos 12, 25 y 26, derivado de una serie de reformas y acciones. Tomado del Centro de estudios de las finanzas públicas, Cámara de diputados del $\mathrm{H}$. Congreso de la Unión, LX Legislatura.

${ }^{8}$ En el Programa Económico enviado por el Ejecutivo Federal al Poder Legislativo en el mes de noviembre de 1997 para su aprobación y entrada en vigor al año siguiente, se planteó la propuesta para la creación del Ramo 33, ello implicó reformar y adicionar un capítulo, el Capítulo V, a la Ley de Coordinación Fiscal, que se tradujo en la creación de la figura "Aportaciones Federales para Entidades Federativas y Municipios", mismo que fue incorporado por primera ocasión al Presupuesto de Egresos de la Federación para el ejercicio fiscal de 1998. Tomado del Centro de estudios de las finanzas públicas, Cámara de diputados del H. Congreso de la Unión, LX Legislatura. 
En este sexenio se crea la Secretaría de Desarrollo Social Estatal para el desarrollo de acciones más específicas en el combate a la pobreza y marginación; tareas que antes desempeñaba otras dependencias públicas como: el Sistema DIF, Secretaría de Salud de Yucatán y la Secretaría de Desarrollo Rural y Pesca.

Se mantiene varias acciones del sexenio anterior, como son los Consejos de desarrollo local como mecanismo de participación democrática que están constituidos con representantes de los diversos grupos sociales, formales e informales, de cada comunidad, los cuales, intervienen activamente en la definición de aquéllos proyectos que le son prioritarios. En la política para la superación de la pobreza, el municipio se convierte en el principal actor para la atención de las demandas sociales de los grupos de mayor rezago social, y como beneficiario directo de la descentralización de atribuciones y responsabilidades.

La aplicación de programas federales no fue la excepción, se llevaron a cabo varios programas de subsidio del ramo 20, operados por diversos organismos dependientes de la Secretaria de Desarrollo Social, instancia competente para atender el problema de la pobreza.

El ramo administrativo 33 "aportaciones federales para entidades federativas y municipios", es junto con el ramo 20, recursos para combatir la pobreza y marginación, cuya canalización a los Estados y municipios constituye un elemento importante para fortalecer y renovar el federalismo, no sólo desde el punto de vista político y económico, sino también dotando de permanencia a los recursos que aporta la federación.

\section{RESULTADOS}

\section{Institucionalización de la pobreza en la agenda pública}

Hoy en día, el tema de la pobreza es una condición imperante en las nuevas políticas públicas no solo a nivel federal sino también estatal y municipal dado la situación de bajos ingresos que viven millones de familias mexicanas. El gobierno ha respondido con instituciones y programas para abatir la pobreza, 
aunque algunos de estos programas pueden ser considerados asistenciales que no contribuyen demasiado al objetivo planteado y que algunos gobiernos los utilicen para fines electorales.

La atención que se le está dando es mayor a la de años anteriores, en gran parte por atender los requisitos de las organizaciones internacionales que subrayan en sus discursos que la situación social que viven varios países en desarrollo pone en peligro la democracia y la estabilidad política. Es contradictorio, dado que el sistema económico que se impone es el gran causante de la pobreza que se vive en varios países, como es el caso de México. Las políticas neoliberales implementadas en México con las sucesivas crisis económicas propias del sistema contribuyeron al incremento del número de personas que no tienen los ingresos suficientes para adquirir la canasta básica.

En el Estado de Yucatán sería hasta el 2001 cuando se institucionaliza el problema de la pobreza en la agenda pública, a partir de la creación de la Secretaría de Desarrollo Social (llamada actualmente Secretaría de Política Comunitaria y Social), en la cual, se responde tardíamente a esta problemática social y económica.

El Estado mexicano institucionaliza el problema de la pobreza en la agenda pública en 1992, cuando se crea la Secretaría de Desarrollo Social (SEDESOL) a partir de la fusión de la Secretaría de Desarrollo Urbano y Ecología (SEDUE) y la Secretaría de Programación y Presupuesto (SPP), quien manejaba el Programa Nacional de Solidaridad (PRONASOL).

\section{Políticas públicas y sistema económico}

La política económica es la estrategia que establecen los países para conducir la economía y se realiza a través de la política monetaria y fiscal que tiende a modificar el comportamiento de los sujetos económicos.

Actualmente, se implementan políticas sociales focalizadoras de corte neoliberal, dejando atrás las políticas del Estado de bienestar basadas en la regulación de precios, ya que contravenían a la política económica neoliberal (sustentada en la competencia y maximización de las ganancias) que se estaba 
gestando en el sistema económico mexicano ${ }^{9}$. Durante ese tiempo, la conducción de la economía tuvo varias modificaciones, el Estado empezó a perder presencia en la economía y las leyes de la oferta y la demanda empezaron a ejercer su hegemonía.

Por ello, la política pública social va a estar definida de acuerdo con el contexto político (democracia, dictadura, oligarquía, etc.) y económico (socialismo y neoliberalismo) que se vive actualmente y rara vez al problema social que se desea atacar, debido a los intereses económicos y políticos del Estado y del país. La aplicación de la política es el resultado del acuerdo entre los distintos grupos de interés.

Cabe mencionar que el sistema político mexicano ha evolucionado con el paso del tiempo y ha influido en la manera de hacer las políticas públicas. Anteriormente, no existía una red institucional de políticas públicas sociales conformada por dependencias de gobierno, instituciones académicas y organizaciones de la sociedad civil, cuyo fin es unir esfuerzos en la implementación de acciones de combate a la pobreza. Años atrás, solo existían redes clientelares que constituían la estrategia del gobierno para la canalización de apoyos a los sectores desprotegidos de la sociedad y que a su vez tenían como objetivo mantener un orden social.

\section{Descentralización y Federalismo}

El pensamiento en la elaboración de políticas públicas ha Estado avanzado, se redefine, en la cual, la sociedad tiene una participación importante, demandando que se atienden los grandes problemas sociales. Durante el análisis de las dos gestiones gubernamentales se observó en el Estado de Yucatán un avance del proceso de descentralización de las políticas sociales a través del manejo de recursos presupuestales marcado en un contexto de un nuevo federalismo donde los tres órdenes de gobierno se coordinan para dar respuesta a las demandas sociales.

${ }^{9}$ Auge neoliberal con Ronald Reagan y Barbara Thatcher. 
Las acciones llevadas a cabo en cada una de las gestiones de gobierno varían según su forma de establecer las estrategias, objetivos y visión a seguir en materia de política social.

La centralización ha demostrado que es insuficiente para resolver las necesidades y aspiraciones de la sociedad, sin embargo, la descentralización, por su parte, conlleva problemas que se desprenden de situaciones añejas y desigualdades sistemáticas. Si bien, no cabe duda que sea fundamental descentralizar el manejo de recursos hacia los niveles en los cuales se tiene conocimiento de primera mano de los problemas y necesidades de la población, la falta de transparencia a nivel estatal y municipal es frecuente, se necesita una profesionalización del servidor público estatal y municipal ${ }^{10}$.

Cada gobierno diseñó su propia política pública social en función a la visión que establecieron, sin embargo, no hubo cambios sustantivos, solo intentos por combatir la pobreza, ya que no contribuyó a que el Estado saliera entre los diez Estados con mayor rezago social. Lo más importante, es la creación de una institución gubernamental encargada de implementar programas sociales articulándose con otras instancias, empezándose a conformar una red de políticas públicas encargadas de combatir a la pobreza.

\section{La pobreza en Yucatán}

La disminución de la pobreza en el país ha sido lenta y con altibajos en el periodo que se estudió. Yucatán no es la excepción, el 70\% de los municipios ha permanecido con grado de marginación muy alto y alto a lo largo de cinco años. En cuanto a pobreza alimentaria, 18 de cada 100 personas la padecen, 26 padecen pobreza de capacidades y 51 padecen pobreza de patrimonio, es decir, es el número de personas que no tiene los recursos para cubrir las necesidades mínimas de alimentación; de educación y salud; y de vestido, calzado, vivienda y transporte público, respectivamente. Yucatán ocupa a nivel nacional el octavo lugar en rezago social con grado alto. Sesenta y un municipios del Estado se ubican en los grados alto y medio de rezago social (CONEVAL, 2005).

\footnotetext{
${ }^{10}$ La profesionalización es la política pública mediante el cual se organizan las normas y los procedimientos administrativos indispensables para garantizar que un cuerpo burocrático cuente con las capacidades profesionales necesarias para cumplir con las atribuciones que le han sido asignadas de manera estable.
} 
En el año 2000, Yucatán ocupó en el ámbito nacional onceavo lugar en cuanto a marginación, siendo Distrito Federal el Estado que obtuvo el menor dato y Chiapas el Estado que obtuvo el mayor dato. En el año 2005, Yucatán repitió la misma posición, siendo Distrito Federal el Estado con el menor dato y Guerrero el Estado con el mayor dato (CONAPO, 2000 y 2005).

Yucatán es un Estado que cuenta con 106 municipios, su población se encuentra muy dispersa y con variadas localidades que tienen poca población y aisladas de sus propias cabeceras municipales mayormente por falta de infraestructura carretera, los hace que queden desajenados de la dinámica económica del Estado (que se desarrolla casi en su totalidad en la Ciudad de Mérida), que en su mayoría existen mercados incompletos (ausencia de mercados y existencia de información asimétrica que crea desinterés del empresario), y poco desarrollados llevando una economía tradicional (se realizan actividades productivas poco tecnificadas). Hoy en día, las economías modernas funcionan solo si el Estado garantiza las inversiones en regiones donde prevalecen mercados incompletos.

Un dato importante, es que la mayor pobreza la padece la población indígena. La marginación y la pobreza son realidades que han acompañado a la población maya de Yucatán a lo largo de su historia (desde inicios de la conquista española) y que se han agravado en las últimas décadas. Más del 30\% de la población yucateca es indígena. El Estado, al momento de elaborar las políticas públicas no tiende a considerar su idiosincrasia, lo que causa un enfrentamiento entre dos culturas.

\section{RECOMENDACIONES}

Una propuesta que se hace en esta investigación es la importancia de desarrollar una Ley Estatal de Desarrollo Social que persiga el objetivo principal de reducir la pobreza, la exclusión y la desigualdad económica y social a través de mecanismos para garantizar los derechos sociales y regular las políticas y programas de desarrollo social, ya que con la creación de una dependencia estatal de Desarrollo Social, llamada actualmente Secretaría de Política Comunitaria y Social, no es suficiente para emprender acciones más definidas y con mayor trascendencia y de corte transversal ya que los Convenios de Desarrollo 
Social, por ejemplo, sólo son acuerdos de voluntades entre la Federación y los Estados, lo que obstaculiza el seguimiento cabal de los programas.

La coordinación y complementariedad entre programas y dependencias, busca evitar las duplicidades y potenciar el efecto total del combate a la pobreza, tomando en cuenta la necesidad de revertir la condición de pobreza de manera multidimensional.

Actualmente el Estado de Yucatán no cuenta con una Ley Estatal de Desarrollo Social, solo se cuenta con ACUERDOS de Coordinación para la distribución y ejercicio de recursos del Ramo Administrativo 20 Desarrollo Social, que suscriben la Secretaria de Desarrollo Social y el Estado de Yucatán. El Acuerdo de Coordinación tiene por objeto coordinar las acciones y recursos entre "LA SEDESOL" y "EL ESTADO", a través de un esfuerzo conjunto y complementario que impulse el trabajo mutuo y corresponsable en materia de superación de la pobreza y marginación, para promover el desarrollo humano, familiar, comunitario y productivo.

Por otra parte, las políticas sociales deben estar basadas en un desarrollo desde lo local, se deben aprovechar las oportunidades y conjurar las amenazas que han significado fenómenos como los procesos globalizadores, la crisis del Estado asistencialista e interventor y la emergencia y revalorización de lo local, con sus secuelas en cuanto a los mecanismos de integración y cohesión social, nuevas correlaciones de poder y de fuerzas, actores e identidades emergentes y nuevos tipos de conflicto social; estos son los grandes retos a los que se enfrentan hoy América Latina. Se requiere de un proceso de desarrollo regional que no se traduzca únicamente en ayudas asistenciales que solamente palien el problema tan añejo de la pobreza mexicana, sino un conjunto de acciones comprensivas y coordinadas que apoyen a las regiones en pobreza para impulsar su desarrollo, como puede ser búsqueda de políticas que crean fuentes de empleo.

Las políticas sociales deben formularse e implementarse de manera incremental, que implica moverse despacio, debido al abanico de intereses económicos y políticos que existen en la economía del Estado. Lo anterior implica una secuencia de cambios pequeños que puedan alterar la distribución del ingreso generado, que con el paso del tiempo se obtiene un resultado 
favorable. Hay que diseñar e implementar políticas sociales que proporcionen los medios necesarios para que la población que este en condición de pobreza establezca sus propios planes de vida y busque los medios adecuados para llevarlos a cabo, y dejar a un lado el asistencialismo que no ayuda lo suficiente en el combate en la pobreza. Además, estas políticas deben tener la característica de ser transversales (que varias dependencias deben participar en el combate a la pobreza, es decir, debe haber corresponsabilidad), de ahí la importancia de legislar a favor de una Ley Estatal de Desarrollo Social.

En general, el gobierno ha fallado en la formulación de una política pública de combate a la pobreza integral a largo plazo, cuyos responsables de su elaboración han permanecido como agentes pasivos, que han afectado seriamente el bienestar social de gran parte de la población mexicana. Los programas sociales compensatorios constituyen un paliativo ineludible en situaciones extremas y no representan un aporte significativo al combate a la pobreza, ya que ésta requiere programas que provean "herramientas" a los sectores pobres para que salgan de la pobreza con su propio esfuerzo y programas que contribuyan a la creación de oportunidades efectivas de integración social. 


\section{REFERENCIAS BIBLIOGRÁFICAS}

1. Canto Sáenz, Rodolfo; (2001); Del henequén a las maquiladoras. La política industrial en Yucatán, 1984-2001. 2001. Instituto Nacional de Administración Pública, UADY; Pág. 105, 106 y 117.

2. Etzioni, Amitai; (2003); La exploración combinada, un tercer enfoque en la toma de decisiones; en Luís Aguilar V.; La hechura de las políticas; Colección Antologías de Política Pública; México, Miguel Ángel Porrua; Pág. 281-282.

3. Lindblom, Charles E.; (2003); La Ciencia de salir del Paso; en Luís Aguilar V.; La hechura de las políticas; Colección Antologías de Política Pública; México, Miguel Ángel Porrua; Pág. 215.

4. Van Meter, Donald S. y Van Horn, Carle E.; (2003); El proceso de implementación de las políticas. Un marco conceptual (1975); en Luís Aguilar V.; La implementación de las políticas; Colección Antologías de Política Pública; México, Miguel Ángel Porrúa; Pág. 99-100.

5. Vargas Paredes, Martín Saúl; (2007); Reforma de la administración pública mexicana. Las redes de política ambiental y forestal en un contexto de democratización; Instituto de Administración Pública del Estado de México; Pág. 64. 


\section{WEBSITE}

1. Consejo Nacional de Población (CONAPO), (2000 y 2005); Índice de Marginación, estimaciones con base en el XII Censo General de Población y Vivienda, 2000 y 2005; <http:/www.conapo.gob.mx> (Consulta: abril de 2007).

2. Consejo Nacional de Evaluación de la Política de Desarrollo Social (CONEVAL); (2007); Evolución de la pobreza en México; <http:// www.coneval.gob.mx/coneval/ > (Consulta: octubre de 2007).

3. Dubois, Alfonso; et. al; Pobreza; (2000); Diccionario de Acción Comunitaria y Cooperación al Desarrollo; < http://dicc.hegoa.efaber.net/listar/mostrar/222 > (Consulta: octubre de 2007).

4. Wagle, Udaye; Volver a pensar la pobreza: Definición y mediciones; http:/ /www.oei.es/salactsi/wagle.pdf; (Consulta: agosto de 2007); Pág. 18-33 